Hope College

Hope College Digital Commons

Faculty Publications

2016

\title{
The Prominence of Affect in Creativity: Expanding the Conception of Creativity in Mathematical Problem Solving
}

\author{
Eric L. Mann \\ Hope College, mann@hope.edu \\ Scott A. Chamberlin \\ University of Wyoming, Scott@uwyo.edu \\ Amy K. Graefe \\ University of Northern Colorado, amy.graefe@unco.edu
}

Follow this and additional works at: https://digitalcommons.hope.edu/faculty_publications

Part of the Educational Psychology Commons, Gifted Education Commons, Other Mathematics

Commons, and the Science and Mathematics Education Commons

\section{Recommended Citation}

Repository citation: Mann, Eric L.; Chamberlin, Scott A.; and Graefe, Amy K., "The Prominence of Affect in Creativity: Expanding the Conception of Creativity in Mathematical Problem Solving" (2016). Faculty Publications. Paper 1419.

https://digitalcommons.hope.edu/faculty_publications/1419

Published in: Creativity and Giftedness, Advances in Mathematics Education, 1 ed. January 1, 2016. Copyright (C) 2016 Springer International Publishing, Switzerland.

This Book Chapter is brought to you for free and open access by Hope College Digital Commons. It has been accepted for inclusion in Faculty Publications by an authorized administrator of Hope College Digital Commons. For more information, please contact digitalcommons@hope.edu. 


\title{
Chapter 5 \\ The Prominence of Affect in Creativity: Expanding the Conception of Creativity in Mathematical Problem Solving
}

\author{
Eric L. Mann, Scott A. Chamberlin, and Amy K. Graefe
}

\begin{abstract}
Constructs such as fluency, flexibility, originality, and elaboration have been accepted as integral components of creativity. In this chapter, the authors discuss affect (Leder GC, Pehkonen E, Törner G (eds), Beliefs: a hidden variable in mathematics education? Kluwer Academic Publishers, Dordrecht, 2002; McLeod DB, J Res Math Educ 25:637-647, 1994; McLeod DB, Adams VM, Affect and mathematical problem solving: a new perspective. Springer, New York, 1989) as it relates to the production of creative outcomes in mathematical problem solving episodes. The saliency of affect in creativity cannot be underestimated, as problem solvers require an appropriate state of mind in order to be maximally productive in creative endeavors. Attention is invested in commonly accepted sub-constructs of affect such as anxiety, aspiration(s), attitude, interest, and locus of control, selfefficacy, self-esteem, and value (Anderson LW, Bourke SF, Assessing affective characteristics in the schools. Lawrence Erlbaum Associates, Mahwah, 2000). A new sub-construct of creativity that is germane and instrumental to the production of creative outcomes is called iconoclasm and it is discussed in the context of mathematical problem solving episodes.
\end{abstract}

Keywords Affect $\bullet$ Creativity $\bullet$ Iconoclasm $\bullet$ Mathematics $\bullet$ Mathematical problem solving

\footnotetext{
E.L. Mann $(\bowtie)$

Hope College, Holland, Michigan, USA

e-mail: mann@hope.edu
}

S.A. Chamberlin

University of Wyoming, Laramie, Wyoming, USA

A. K. Graefe

University of Northern Colorado, Greeley, Colorado, USA 


\subsection{Introduction}

Mathematics is a human endeavor. Yet, it is often portrayed in the K-12 classroom as a tool to communicate information or help answer questions encountered in daily life, overshadowing the creativity that spawned the rules and algorithms children work so diligently to master. Studies of the creative works of eminent mathematicians often mention curiosity and a willingness to embrace challenge as necessary attributes of creativity. Movshovitz-Hadar and Kleiner (2009) stress the importance of courage as well - both the social courage needed to take a risk and the intellectual courage to follow a path not knowing if the end result will bring success or failure. Several examples offered by Movshovitz-Hadar and Kleiner include the work of Janos Bolyai and Nicolai Loabachevsky. Both had the intellectual courage to ask, "What if parallel lines do meet?" and the social courage to share their work with the world. Both were discouraged from pursing this line of study. Bolyai was discouraged by both his father and Gauss who claimed to have made the same discovery earlier but did not seek to publish for fear of controversy. Loabachevsky was named the "madman of Kazan" when his manuscript was rejected by the St. Petersburg Academy of Sciences. Yet their courage to persist provided the geometric basis for the understanding of physical time and space (Cannon et al. 1997). For a more indepth discussion of courage and mathematical creativity and several more examples of mathematical creations initially viewed as heretical see Movshovitz-Hadar and Kleiner.

A seminal work in mathematical creativity is Hadamard's (1945) essay, The Psychology of Intervention in the Mathematical Field, in which he summarizes and extends the work of others seeking to understand the process of mathematical thought. In that work, Hadamard discusses various types of mathematical minds and the products that they may create. He classified these mathematical minds as either logical (those that follow predetermined conventions, routines, or procedures) or intuitive (those that are often guided by common sense). One of the challenges for intuitive problem solvers, according to Hadamard, is that they need to have the courage to share their answers with peers and the mathematical community. As an example, Hadamard describes a situation in which a student, "guided by common sense, knew the right answer to my question, but did not feel he was allowed to give it and did not realize that ...[it] could be easily translated into a rigorous and correct proof" (p. 105-106). He also shares a note found in Riemann's papers that read, "These properties of $s(\mathrm{~s})$... are deduced from an expression of it which, however, [sic] I did not succeed in simplifying enough to publish it" (p. 118). In the first example the student's lack of courage resulted in a lost opportunity to develop his mathematical talent and understanding. In the second example, Riemann's courage in sharing his work, even though he had not arrived at a publishable-ready expression, brought new insight to the study of prime numbers. For more on the search for 
a proof for the properties of the Riemann Zeta function, see the Clay Mathematics Institute's Millennium Problems. ${ }^{1}$

The difference between Hadamard's student and Riemann or Bolyai and Gauss was the courage to take a risk, to ask a question, to act on intuition, and to share ideas. Without that courage, potentially creative mathematical ideas remain unknown and unexplored; students are left to follow systematic solution paths without exploring the synthesis of thought that is necessary to develop mathematical understanding (Hadamard 1945). Hadamard refers to intuitive problem solvers working with almost reckless abandon in seeking solutions, and he borrows Poincaré's terminology when he refers to them as "bold cavalrymen of the advance guard seeking conquests" (p. 106).

Conquests are rarely achieved by simply doing what has always been done. Rather, mathematical conquests are gained by some level of risk taking (reckless abandon) and the courage to pursue a line of thought or an approach that often challenges iconic (conventional or traditional) practices and beliefs, hence an iconoclastic view of mathematical creativity. In this chapter the authors propose iconoclasm as a necessary fifth component in developing an understanding of mathematical creativity.

\subsection{Creativity and Mathematics}

Analysis of the literature affirms the fact that creativity is multifaceted in the field of mathematics education (Mann 2006, 2009; Sriraman 2006). Nevertheless, four components that recur in nearly all creativity literature are fluency, flexibility, originality, and elaboration. In this section, these four components are discussed.

Fluency, or the number of relevant responses that can be created by any one individual, is an indicator of creativity. Often compared to brainstorming, fluent thinkers are able to generate many ideas, possibilities, and potential approaches to finding solutions to a problem. Generation of ideas is the focus here, though once completed, creativity assessment evaluations do consider the relevancy of the responses. For example, in scoring a stimulus response on the Torrance ${ }^{\circledR}$ Tests of Creative Thinking figural forms (Torrance et al. 2008), the evaluator is instructed to score responses based on the relevancy and meaningfulness of the response.

Flexibility in thinking (Krutetski 1976; Torrance 1966) is considered one's ability to think about a problem solving task from more than one perspective and/or to reverse mental processes. It is not uncommon for problem solvers working on a task to be constrained by a preconceived solution path. This is especially true when the predominant "view of school mathematics is one of rules and procedures, memorization and practice, and exactness in procedures and answers" (Linquist 1997, p. xiv).

\footnotetext{
${ }^{1}$ http://www.claymath.org/millenium-problems/riemann-hypothesis
} 
This is a limited view of mathematics in which mathematical creativity does not have the freedom to develop.

Ervynck (1991) outlined the development of mathematical creativity as a series of stages with algorithmic activity as precursors to creative activities. When producing creative solutions, it is necessary to be able to draw on the foundational knowledge of the technical and computational aspects of mathematics. However, when the emphasis does not transition to the next stage of development, the student is stuck in the view of mathematics as a world of right and wrong answers (Ginsburg 1996). When this happens, flexibility is generally precluded and individuals are locked into searching for the "right" solution path rather than looking for multiple paths to a solution. With sufficient mathematical knowledge and experience, flexible thinkers can evaluate the results for appropriateness and elegance. Developing adaptive expertise (National Research Council 2000) is important for successful learning: "Adaptive experts are able to approach new situations flexibly ... they don't simply attempt to do the same things more efficiently; they attempt to do things better" (p. 48). Developing the ability to be flexible in one's approach to problem solving is essential for creative development. As an example, if a mathematical problem was provided in which most problem solvers used number sense to solve the problem, a flexible thinker may revise an initial solution to find a more efficient approach or look for connections to other mathematical domains such as statistics and probability or algebra. A highly flexible individual may chart new waters simply by having the courage asking 'what if' in looking for a better approach. Questioning the validity of Euclid's fifth postulate, the parallel postulate, was a significant 'what if' that challenged centuries of mathematical study and created new discoveries in mathematics with many applications in a universe much bigger than the ancient Greeks ever imagined. Flexible thinkers lend themselves to highly creative solutions due to their ability to think 'in addition' to the manner in which others might typically think.

Often the concepts of flexibility and fluency are confused. While fluency is considered the number of responses generated, flexibility is focused on the variety of approaches that an individual is able to use in solving a problem. From a research/ assessment perspective, blurred lines between constructs can be problematic; in practice, the two constructs go hand-in-hand. As an example, the National Council of Teachers of Mathematics (2014) position statement on procedural fluency invokes a focused perspective on flexibility, calling it,

...the ability to apply procedures accurately, efficiently and flexibly, to transfer procedures to different problems and contexts; to build or modify procedures from other procedures ... building on familiar procedures as they create their own informal strategies and procedures.

Originality, the ability to create novel responses, was initially considered the only measure of creativity (Chassell 1916) and is likely the most regularly used 
synonym by those not familiar with creativity research. It may be common for teachers to only see highly creative products in mathematics classrooms as ones that are original or novel. The ability to create novel products (e.g., physical models, mathematical models, or on-paper prototypes) serves as one piece of evidence that creative potential exists. Along with the aforementioned manifestations of originality, it is important to note that mathematical processes, procedures, and algorithms also can be highly original. A view of originality as something new to the world on par with the works of Euler, Gauss, Cantor, and da Vinci, among many others, is a narrow view of the construct. Attaining this level of creative recognition, legendary Big-C status, (Csikszentmihalyi 1999) is a complex task often not achieved in a creator's lifetime. Kaufman and Beghetto (2009) offered a broader view in their Four C Model of Creativity that presents different dimensions of creativity and originality. In this model, the developmental progression of creativity is recognized as inherent in the learning process:

- Mini-c: Novel and personally meaningful interpretation of experiences, actions, and events.

- Little-c: Everyday expressions of novel and task appropriate behaviors, ideas, or products

- Pro-c: Expert expressions of novel and meaningful behaviors, ideas, or products

- Big-C: Legendary novel and meaningful accomplishments, which often redirect an entire field of study or domain

Assessments attempting to identify creative potential in individuals are focused on the mini-c and little-c levels of creativity. Society, however, generally assesses Pro-c and Big-C. As a short side conversation, some debate exists about whether a problem's solution needs to be useful and utilitarian to be considered creative. On one hand, Amabile (1996) asserts that a solution needs to be appropriate to the task, and Torrance $(1966,2008)$ asserts that solutions need to be interpretable, meaningful, and have relevant ideas. Sriraman (2006), however, argues that problem solving solutions can be highly theoretical and not have any immediate or direct applications. It may be the case that the application of a highly theoretical solution will realize its significance long after created (e.g., many decades), thus substantiating Sriraman's point.

For several years, creativity in mathematics was comprised of only fluency, flexibility, and originality (Haylock 1997; Kim et al. 2003; Tuli 1980). More recently, the notion of elaboration (Imai 2000) was connected to creativity in mathematics. Elaboration pertains to the ability of an individual to provide depth beyond what most problem solvers can provide in an explanation. Individuals with a high degree of elaborative skill may identify and be capable of expounding on intricacies of a solution that many peers may not recognize. 


\subsection{Affect and Creativity}

Positive affect (feelings, emotions, dispositions and beliefs) have been associated with the creative process (Eubanks et al. 2010; Leu and Chiu 2015). Much of the research in this area is focused on developing a work place environment to encourage creativity (Amabile et al. 2005; Bledow et al. 2013) and in the field of social psychology (Baas et al. 2008; Jauk et al. 2014; Nijstade et al. 2010). A common premise in these studies is that affective states play a significant role in stimulating creative thinking and is a factor that can be influenced.

Amabile et al. (2005) studied the relationship between an individual's affective state and their daily creative activities in the work place. Their findings suggest that affect plays a more prominent role in organizational theories of creativity than previously thought and that these findings might extend beyond the study of creativity in the work place to a broader concept of the nature of creativity.

In their Dual Pathway to Creativity Model, Nijstad et al. (2010) theorized that creativity could be achieved via a flexibility pathway or a persistence pathway. The flexibility pathway acknowledges prior work in assessing flexibility, fluency, and originality with respect to creativity. This pathway is associated with breaking away from habitual thinking and the ability to switch flexibly between multiple approaches to a task. The persistence pathway acknowledges that creative ideas may also emerge as a result of hard work and systematic, in-depth explorations of a few perspectives. While one might infer that these two pathways are somewhat diametrically opposed, Nijstad, De Dreu, Reitzschel and Baas suggest that the creative individual may switch between pathways over the course of solving a problem. Applications of this model in seeking to improve creativity in the work place are readily apparent as are connections to several of the Mathematical Practices in the Common-Core State Standards - Mathematics (National Governors Association Center for Best Practices and Council of Chief State School Officers 2010).

While most of the work in this area is recent, Fiest's 1998 meta-analysis of personality and creativity concluded, "that in general, a "creative personality" does exist and personality dispositions do regularly and predictably relate to creative achievement" (as cited in Runco 2014, p. 267). Seminal work done by Donald MacKinnon at the Institute for Personality Assessment and Research (IPAR) still holds true today (Runco 2014). MacKinnon identified lability as a measure of creativity. His colleague, Harrison Gough noted that, "though there is a facet of high ego strength in this scale [lability], an adventurous delighting in the new and different and a sensitivity to all that is unusual and challenging, the main emphasis seems to be on an inner restlessness and inability to tolerate consistency and routine" (as citied in Runco 2014, p. 269).

The inability to tolerate consistency and routine is mirrored in Goldin's (2009) issues of integrity and intimacy. When mathematics is taught as mainly a series of rules and procedures, serious issues of integrity may arise for the child. She writes, "at some level, I would conjecture, the child knows that something is missing... children who have greater mathematical ability and potential for developing 
inventiveness are likely to have the more serious integrity issues around conceptual understanding" (p. 190). Eventually these integrity issues result in one of three outcomes for the child: (1) take a risk and pose a question, (2) accept the lack of meaning, or (3) assume that I am not good with math. Mathematical problem solving is an intimate task, one in which the individual invests a significant amount of attention and energy in seeking a solution. It takes social courage to present a new approach or idea publicly, especially when it may challenge the accepted truth as conveyed by the teacher or textbook.

Goldin's (2009) concluding thoughts connect to MacKinnon's construct of lability (see Runco 2014), to Nijstad et al. (2010) Dual Pathway to Creativity Model, and to Movshovitz-Hadar and Kleiner (2009) discussion of courage. She writes:

Thoughtful attention [to] the affective domain can result, over many years, in a kind of strength of purpose in the pursuit of mathematical understanding. Then the growing child builds affective structures that literally last a lifetime, enabling continuing curiosity and mathematical persistence and perseverance, representing essential information, evoking powerful problem-solving heuristics and learning strategies, stimulating inventiveness and following out the resulting ideas, and promising the continuing thrill and long-term satisfaction associated with the achievement of new mathematical insights (p. 193).

\title{
5.4 Mathematical Problem Solving
}

In his work, Mathematics as a Creative Art, Halmos (1983) wrote:

\begin{abstract}
Mathematics - this may surprise you or shock you some - is never deductive in its creation. The mathematician at work makes vague guesses, visualizes broad generalizations, and jumps to unwarranted conclusions. He arranges and rearranges his ideas, and he becomes convinced of their truth long before he can write down a logical proof. The conviction is not likely to come early - it usually comes after many attempts, many failures, many discouragements, and many false starts ( $\mathrm{p} 256-257)$.
\end{abstract}

Mathematical problem solving (MPS) differs from the mathematical exercises on which K-16 students spend time working to develop mathematical technical skills, exercises often comprised of repetitive tasks in which students are asked to find answers to a series of short, similar exercises. MPS tasks used to develop creativity are not dissimilar from the work of mathematicians as described by Halmos. Indeed they "are ones for which students have no memorized rules, nor for which they perceive there is one right solution method. Rather, the tasks are viewed as opportunities to explore mathematics and come up with reasonable methods for solution" (Hiebert et al. 2000, p. 8).

As with the construct of mathematical creativity, MPS continues to be studied and the basic concept expanded. MPS simultaneously enjoys and suffers from multiple operational definitions. Chamberlin (2008) in a survey of 20 mathematics education experts from North America, Europe, and Israel, refined the conception of MPS in a Delphi Study, ultimately defining it as comprised of both processes and characteristics. The most commonly agreed upon processes were: (1) engaging in 
cognition, (2) seeking a solution, (3) communicating ideas, (4) engaging in iterative cycles, (5) defining mathematical goals, and (6) mathematizing situations to solve problems. Regarding characteristics, the best problem solving tasks can: (1) be solved with more than one tool and more than one approach, (2) be used to assess level of understanding, and (3) require the implementation of multiple algorithms for a successful solution.

\subsection{Iconoclasm}

"Dare to be a radical, but don't be a damn fool," (Baron as cited in Runco 2014, p. 275). In his writing about the relationships between creativity, personality and motivation, Runco shares with his reader descriptors of the creative individual from a variety of scholars such as independent, non-conformist, rebellious, unconventional, norm-doubting, and contrarian. Also in 2014, the authors ${ }^{2}$ proposed adding iconoclasm to flexibility, fluency, originality, and elaboration as components to measure creative potential. Iconoclasm differs from the four previous components in that they are manners through which creative products are manifested during mathematical problem solving episodes, while iconoclasm is an affective state that must be met for creativity to emerge.

Iconoclasm pertains to affect (feelings, emotions, dispositions, and beliefs) more than it does to cognition, though the two are intricately intertwined. In essence, if one perceives either restrictive policies within an educational environment (such as strict adherence to textbook solution methods) or the classroom teacher (with all the "right" answers) as the ultimate authority, then the individual's creative abilities will likely be curtailed. As iconoclasm pertains to the world of psychology of mathematics, MPS, and creativity, it may be considered unthinkable to challenge conventions in MPS as perhaps less than efficient. As an example, a teacher of young elementary students may be stuck with a partial products method to multiply several digit numerals because the textbook expects students to learn multiplication in that manner. However, a promising young mathematician may find a more efficient and insightful manner to conduct multiplication and share it with the class. When this is done, the act of iconoclasm has occurred.

Another way in which iconoclasm varies from the previous four subcomponents of creativity is that it precedes creative product output rather than being manifested in the products. That is to say that without iconoclasm, the remaining four sub constructs would never be considered germane to the study of mathematical creativity because, although there would continue to be mathematical products, few would be creative.

Mathematical problem solvers that have substantial levels of iconoclasm are theoretically more likely to recognize novel solutions, possibly because they may not experience (or have learned to embrace) high levels of anxiety, common to

\footnotetext{
${ }^{2}$ Chamberlin and Mann 2014.
} 
many others, when solving a problem. Additionally, such problem solvers may choose not to employ commonly accepted algorithms simply to deviate from peer problem solvers, and they may do it with relatively low anxiety (a higher level of intellectual courage). Moreover, they may be inclined to share their solution(s) with peers with very little fear of how they will be perceived (high level of social courage).

Iconoclasm has its roots in religion and technically translates to the breaking of icons. The interpretation of iconoclasm from centuries ago pertains to tearing down or attacking cherished idols, a rebellious act viewed as dissension or heresy. More recently, the term iconoclast has surfaced and pertains to the person that precipitates or originates an act of iconoclasm. The two applications of iconoclasm, in religion and in the mathematical problem solving sense, converge in that in each instance, the commonality is courage to deviate from what is expected, while the default is to accept commonly held beliefs, such as algorithms, without question. In the religious context, courage is required to challenge cherished idols and is often undertaken at great risk to personal safety. Though situations in mathematical settings (e.g., a mathematics classroom) may not be life threatening, a problem solver also needs courage to deviate from the norm in order to identify potentially creative solutions and then to share such solutions with peers and teachers. The term potentially is important here - not all creative attempts at solving a problem will be successful but having the courage to share an approach offers opportunities for collaboration and discourse that may eventually result in a successful solution (Halmos's vague guesses, broad generalizations, unwarranted conclusions).

For example, if two students are solving the same problem and the student with the higher degree of iconoclasm is confident in sharing a highly creative problem solving solution (e.g., one that is particularly original/novel with respect to the "taught" methods or other approaches in the classroom), then the teacher's willingness to listen to the solution and provide constructive feedback rewards the attempt and encourages further exploration. On the contrary, the student with a low degree of iconoclasm may be fearful that the teacher will not be receptive to an alternate solution, so the student may have little impetus to follow through or invest the energy in producing and/or sharing a highly creative response. If unsuccessful, it is not unreasonable to assume this student labels either the problem as too hard or his abilities as inadequate - both of which are unfortunate and avoidable outcomes. While the second student may benefit from observing the teacher's interactions with the first student, encouraging a more iconoclastic approach to future mathematical problem solving activities, it is all too common to see students disengage with an "I'm just not good at math" attitude when struggling with a problem. The teacher is thus challenged to use all the pedagogical skills at his or her disposal to encourage students to "solve problems in novel ways and post new mathematical questions of interest to investigate" (Johnsen and Sheffield 2012, p. 16).

In short, the teacher or learning facilitator needs to create a favorable environment (Amabile et al. 2005; Bledow et al. 2013; Goldin 2009; Hiebert et al. 2000; Merkel et al. 1996) for individuals to manufacture creative products. In this climate, all students benefit. However, in situations in which the teacher does not create a 
climate conducive to the emergence of creative products, it is likely that only students with a high degree of iconoclasm will be inclined to develop creative products, despite the fact that students with low levels of iconoclasm may have similar levels of creative potential. This is because individuals that are not fearful of higher authorities or peers likely have lower levels of anxiety, higher self-efficacy and selfesteem, and a better attitude about mathematical problem solving.

Fluency, flexibility, originality, and elaboration are manners in which creative products are measured and have been investigated to a large degree. Individuals that study creativity in mathematics value creative output by asking whether such products were highly novel (original), added to the number of solutions (fluency), exhibited high degrees of flexibility in thinking, or added to the depth of explanations (elaboration). Runco and Albert's (1986) Threshold Theory of Creativity found a relationship between creativity and intelligence up to a point ( 120 IQ). Feldhusen and Westby (2003) determined that an individual's knowledge base is the fundamental source of his or her creative thought. Bern (2008), writes about his efforts to understand the neurological base of creativity in his non-technical book, Iconoclast: A Neuroscientist Reveals How To Think Differently. Bern's book reviews the lives of several well-known iconoclasts and introduces the reader to the field of neuroeconomics, a multi-disciplinary discipline less than two decades old, that seeks to understand human choice and decision making (for a brief history of neuroeconomics see Glimcher et al. 2009). While Bern does mention creativity briefly, there is no connection made to creativity research literature. That said Sternberg (2009) finds merit in Bern's work, especially the recognition of iconoclasticty as a quality that can be developed, a necessary condition to the study of means to develop creativity by encouraging iconoclasm. Combined, these various approaches to understanding the nature of creativity suggest that a combination of some degree of intelligence, knowledge, and iconoclasm are necessary for creative products to emerge from problem solvers. While there is a body of research to support the first two conclusions, research is needed to develop the means to assess an individual's level of iconoclasm in mathematical problem solving situations and to explore the relationships with other contributing factors.

\subsubsection{Examples of Iconoclasm in Mathematics}

It appears as though iconoclasm has always been a trait of creative mathematics because each novel revolutionary mathematical idea is met with skepticism, and it often requires significant time for the field to accept the new paradigm (MovshovitzHadar and and Kleiner 2009). Negative numbers, for example, were initially thought to be a pointless idea and therefore not relevant to mathematics. The Chinese were originally credited with conceiving the idea of negative numbers, though the Greeks (Diophantus, specifically) used them with some degree of regularity to explore concepts in what is now known as algebra some 500 years later (Rogers 2014). In 620 $\mathrm{CE}$, the Indians saw use for them in the context of fortunes and debts. Despite Greek 
use of negative numbers, Europeans were not wholly accepting of them until around 1400 AD (Rogers). As recent as the 1800s, only 200 years ago, some such as Carnot (in 1803) and Busset (in 1843) did not accept negative numbers as a workable concept in mathematics (Boyé no date). In fact, Busset saw negative numbers as the reason that mathematics was difficult to teach. Busset went so far as to mention that mental aberrations, such as the concept of negative numbers, might prevent gifted minds from studying mathematics (Boyé). It is thus readily apparent that a significant portion of mathematics, commonly accepted by today's mathematicians and introduced to students in grade 6 (Common Core Standards Writing Team 2012), was, at one time, a subject of much debate.

A characteristic that mathematically creative individuals may possess is iconoclasm. This is because they may feel more comfortable or less anxious posing solution paths to problem solving tasks that are not commonly accepted solutions than peers without similar levels of courage. Few have discussed the reason for the emergence of creative output. In other words, why does a mathematical problem solver pursue highly creative solutions? This is the point at which iconoclasm, as a necessary aspect of creativity, begins to take meaning. Within the construct of iconoclasm, individuals seek creative and innovative solutions to mathematical problems because they feel that the currently agreed upon solutions are not adequate or they are convinced that their solution can add to the body of knowledge in a particular mathematical content area. In some cases, iconoclastic problem solvers (i.e., those with high degrees of iconoclasm) may seek innovative solutions because they want to stand out among colleagues. Few educational psychologists have contemplated the reason why creative products emerge from individuals. In considering one's motive to create a new solution, the psychological constructs of affect in MPS (McLeod and Adams 1989), such as feelings, emotions, and dispositions, are considered relative to why individuals are creative. With the commonly used constructs of creativity (e.g., fluency, flexibility, originality, and elaboration), the discussion of why creativity emerges is rarely considered. With motivation being the sum-total of affect (Anderson and Bourke 2000), the theory of iconoclasm suddenly warrants serious consideration as a component of creativity because it explains why problem solvers create solutions to tasks. More specifically, problem solvers with high degrees of iconoclasm may be motivated to be different and/or more efficient, explicit, or novel than peers.

Giftedness, like mathematical problem solving, has many conceptions. A commonly accepted conception of giftedness is Renzulli's Three-Ring Conception of Giftedness (1978) in which he defined it as being comprised of above average ability, task commitment, and creativity. Regarding task commitment, Renzulli (1998) uses the terms perseverance, determination, dedication, high levels of interest, enthusiasm, and fascination, all of which are components of motivation. Subsequently, Renzulli added co-cognitive traits through his Operation Houndstooth (Renzulli 2002) research. Each of the six areas outlined by Renzulli in Operation Houndstooth (i.e., optimism, courage, romance with a discipline, sensitivity to human concerns, vision, and physical/mental energy) has a strong connection to the affective domain and adds fuel to the discussion of why problem solvers seek solutions. 
Baer and Kaufman's Amusement Park Theory of Creativity (2005) seconds this notion with initial requirements for the emergence of creativity, or as they call it, the 'ticket into the park,' which includes intelligence, motivation, and the environment.

\subsubsection{Relationship of Iconoclasm to Fluency, Flexibility, Originality, and Elaboration}

Given an established relationship between iconoclasm and motivation, one may wonder about the interrelationship between iconoclasm and the remaining four components of creativity (i.e., fluency, flexibility, originality, and elaboration). The theory of iconoclasm as a fifth construct of creativity in mathematics helps researchers understand the connection of the remaining four. This is because it explains the motive for creativity as Forgeard and Mecklenberg (2013) attempted. Critical to their work was the component of intrinsic motivation in relation to the generation of creative products. Further, they utilized the concept of pro-social motivation (Grant and and Berg 2010), which Forgeard and Mecklenberg distinguish as "one's desire to contribute to other peoples' lives" (pp. 255, 257). When iconoclasm is viewed relative to motivational factors, for example pro-social motivation, its relationship to the four subcomponents of creativity is revealed; the iconoclast has an intrinsic need to find a better solution. Prior to realizing that iconoclasm may have this degree of interaction with the model of creativity, the four accepted sub-constructs were largely disparate facets (with the exception of flexibility and fluency in thinking).

While examples abound of iterative improvements in things that were once "good enough" in the our daily life (e.g. each new generation of cell phones is more efficient, multidimensional, smaller, and faster), often in a classroom setting finding the anticipated answer by a prescribed path is highly valued. The motive for individuals seeking more than one solution, or fluency, to a problem may be to identify the most efficient solution, thus placing themselves in a position to capitalize on the most sophisticated and quickest method in future situations. In many cases, the impetus for fluency, or a greater number of options in solution paths, pertains to problem solvers wanting more options than they currently have. To accomplish this objective, problem solvers may need to be iconoclastic and challenge the system (e.g., teacher or textbook) in order to identify a greater number of solution paths. In many cultures, be it a country, classroom, or work environment, it may be unacceptable to challenge a system that is already producing adequate results. Iconoclastic problem solvers, however, may feel that "good enough" just is not good enough and thus seek a more efficient solution path than what their environment accepts. Fluency and flexibility are intricately intertwined in the respect that individuals may seek novel perspectives because they feel the process may prove fruitful in a particularly original solution path. The solution path may have positive social outcomes thus reinforcing the decision to challenge the system. 
The use of multiple representations may help develop an increased number of solution paths. As an example, van Dyke and Craine (1997) suggest that algebra has at least four representations (i.e., verbal statement or text, equation, table of values, and graph) that can be utilized to solve a problem. Elaboration during problem solving may provide opportunities to create new solutions because, in explaining solutions, flaws may be uncovered. Ideally, through this process, novel solution paths are precipitated. After all, if the previous solutions were acceptable and worked well, the impetus to explore additional representations may only emerge if there are reasons to examine the processes used in depth.

In identifying such inadequacies in commonly accepted solutions or algorithms, creative problem solvers are intrinsically driven, or have a motivation, (Forgeard and and Mecklenburg 2013) to identify a more creative, sophisticated, or innovative solution because the need exists, if only from a pro-social perspective. They may also develop the solution out of pure enjoyment or aesthetic appreciation of mathematics as Krutetskii (1976) suggests. Csikszetentmihalyi (2014) writes, "the creative person cannot be entirely invested in the commonly accepted conceptual configurations of his or her domain...a creative person should be dissatisfied with the state of knowledge and be motivated to search for alternatives" (p. 164). This dissatisfaction may manifest itself in a young child inventing her own multiplication and division algorithms (Ambrose and et al. 2003) or in a seasoned mathematician questioning a long accepted "truth" in mathematics and disputing it. ${ }^{3}$ Alternatively, highly creative individuals in mathematics may opt not to seek alternate solutions in MPS situations if they perceive the problem as uninteresting, lacking challenge, and thus unworthy of devoting additional creative and cognitive resources or if they are sufficiently pleased with the solution provided. In this respect, the iconoclastic nature of a creative problem solver must be awakened to realize a need for a better solution.

\subsection{Areas for Future Research}

One of the aspects of educational psychology that makes it a well-respected discipline is the reluctance of the field to accept newly proposed theories without empirical evidence to substantiate them. Consequently, researchers interested in iconoclasm in mathematical problem solving have several options. Foremost among them is the development of an instrument to investigate whether iconoclasm, in the form of challenging commonly accepted algorithms, is something that mathematics problem solvers will embrace when faced with a relatively inefficient solution. The work of Leu and Chiu (2015) and Tjoe (2015) are moving the field in this direction. Chamberlin (2010) has developed the Chamberlin Affective Instrument for

\footnotetext{
${ }^{3}$ Euler's sum of power conjecture stood for almost 200 years before a short paper (two sentences) was published in the Bulletin of the American Mathematical Society disproved the theory (Lander and and Parkin 1966).
} 
Mathematical Problem Solving (Chamberlin and Powers 2013), and the authors are now working to construct and validate an integrated assessment tool. Paper and pencil assessments often lack the "intimacy" needed to understand the thought process and affective engagement involved in creative problem solving activities. Krutetskii's (1976) approach of having mathematical problem solvers create solutions, look at their solutions for evidence of creativity, and then interview such individuals in an attempt to understand their thought process is difficult to use with large sample sizes, yet offers the opportunity to explore deeply the level of iconoclasm in individual responses. In the end, the construct of iconoclasm needs to be empirically tested, and while several prospective approaches appear to exist for such an investigation, multiple studies are needed.

Note An earlier version of this chapter was presented as a concept paper at the 8th International Conference on Creativity in Mathematics and Education of Gifted Students, Denver, Colorado. 2014.

\section{References}

Amabile, T. M. (1996). Creativity in context. Boulder: Westview Press.

Amabile, T. M., Barsade, S. G., Mueller, J. S., \& Staw, B. M. (2005). Affect and creativity at work. Administrative Science Quarterly, 50, 367-403. http://dx.doi.org/10.2189/asqu.2005.50.3.367

Ambrose, R., Baek, J., \& Carpenter, T. P. (2003). Children's invention of multidigit multiplication and division algorithms. In A. J. Baroody \& A. Dowker (Eds.), The development of arithmetic concepts and skills: Constructive adaptive expertise (pp. 307-338). New York: Routledge.

Anderson, L. W., \& Bourke, S. F. (2000). Assessing affective characteristics in the schools. Mahwah: Lawrence Erlbaum Associates.

Baas, M., De Drew, C. K. W., \& Nijstad, B. S. (2008). A meta-analysis of 25 years of mood-creativity research: Hedonic tone, activation, or regulatory focus? Psychological Bulletin, 134, 779-806. http://dx.doi.org/10.1037/a0012815

Baer, J., \& Kaufman, J. C. (2005). Bridging generality and specificity: The amusement park theoretical (ABT) model of creativity. Roeper Review, 28, 158-163. http://dx.doi. org/10.1080/02783190509554310.

Berns, G. S. (2008). Iconoclast: A neuroscientist reveals how to think differently. Cambridge, MA: Harvard Business School Press.

Bledow, R., Rosing, K., \& Frese, M. (2013). A dynamic perspective on affect and creativity. Academy of Management Journal, 56, 432-450. http://dx.doi.org/10.5465/amj.2010.0894

Boyé, A. (no date). Some elements of history of negative numbers. Unpublished manuscript. Retrieved from http://www.gobiernodecanarias.org/educacion/3/Usrn/fundoro/archivos\%20 adjuntos/publicaciones/otros_idiomas/ingles/penelope/Boye_negativos_en.pdf

Cannon, J. W., Floyd, J. W., Kenyon, R., \& Parry, W. R. (1997). Hyperbolic geometry. In S. Levy (Ed.), Flavors of geometry (Mathematical Sciences Research Institute Publications, Vol. 31). Cambridge, UK: Cambridge University Press.

Chamberlin, S. A. (2008). What is problem solving in the mathematics classroom? Philosophy of Mathematics Education, 23, 1-25.

Chamberlin, S. A. (2010). A review of instruments created to assess affect in mathematics. Journal of Mathematics Education, 7, 167-182.

Chamberlin, S. A., \& Mann, E. L. (2014, July 27-30). A new model of creativity in mathematical problem solving. In Proceedings of the international group for mathematical creativity and 
giftedness (pp. 35-40). Denver: University of Denver, CO. Retrieved from http://www.igmcg. org/images/proceedings/MCG-8-proceedings.pdf

Chamberlin, S. A., \& Powers, R. (2013). Assessing affect after mathematical problem solving tasks: Validating the Chamberlin affective instrument for mathematical problem solving. Gifted Education International, 29(1), 69-85. http://dx.doi.org/10.1177/0261429412440652

Chassell, L. M. (1916). Tests for originality. Journal of Educational Psychology, 7, 317-328. http://dx.doi.org/10.1037/h0070310

Common Core Standards Writing Team. (2012). Progressions for the common core state standards in mathematics (draft): $K-5$, number and operations in base ten. Tucson: Institute for Mathematics and Education, University of Arizona. Retrieved from http://commoncoretools. me/wp-content/uploads/2011/04/ccss_progression_nbt_2011_04_073_corrected2.pdf

Csikszentmihalyi, M. (1999). Implications of a systems perspective for the study of creativity. In R. J. Sternberg (Ed.), Handbook of creativity (pp. 313-335). New York: Cambridge University Press.

Csikszentmihalyi, M. (2014). Motivation and creativity. Towards a synthesis of structural and energistic approaches to cognition. In M. Csikszentmihalyi (Ed.), Flow and the foundation of positive psychology: The collected works of Mihaly Csikszenthihalyi (pp. 155-173). Dordrecht: Springer. Reprinted from New Ideas in Psychology, 6(2), 159-176. 1988.

Ervynck, G. (1991). Mathematical creativity. In D. Tall (Ed.), Advanced mathematical thinking (pp. 42-53). Dordrecht: Kluwer Academic Press.

Eubanks, D. L., Murphy, S. T., \& Diaz, M. D. M. (2010). Intuition as an influence on creative problem-solving: The effects of intuition, positive affect, and training. Creativity Research Journal, 22, 147-159. http://dx.doi.org/10.1080/10400419.2010.481513

Feldhusen, J. F., \& Westby, E. L. (2003). Creativity and affective behavior: Cognition, personality and motivation. In J. Houstz (Ed.), The educational psychology of creativity (pp. 95-103). Cresskill: Hampton Press.

Forgeard, M. J. C., \& Mecklenburg, A. C. (2013). The two dimensions of motivation and a reciprocal model of the creative process. Review of General Psychology, 17, 255-266. http://dx.doi. org/10.1037/a0032104.

Ginsburg, H. P. (1996). Toby's math. In R. J. Sternberg \& T. BenZeev (Eds.), The nature of mathematical thinking (pp. 175-282). Mahwah: Lawrence Erlbaum.

Glimcher, P. W., Camerer, C. F., Fehr, E., \& Poldrack, R. A. (2009). Introduction: A brief history of neuroeconomics. In P. W. Glimcher, E. Fehr, C. Camerer, \& R. R. Poldrack (Eds.), Neuroeconomics: Decision making and the brain (1st ed., pp. 1-12). New York: Academic. Retrieved from http://www.decisionsrus.com/documents/introduction_a-brief-history-ofneuroeconomics.pdf

Goldin, G. A. (2009). The affective domain and students' mathematical inventiveness. In R. Leikin, A. Berman, \& B. Koichu (Eds.), Creativity in mathematics and education of gifted students (pp. 181-194). Rotterdam: Sense Publications.

Grant, A. M., \& Berg, J. M. (2010). Pro-social motivation at work: When, why, and how making a difference makes a difference. In K. S. Cameron \& G. M. Spreitzer (Eds.), The Oxford handbook of positive organizational scholarship (pp. 28-44). New York: Oxford University Press.

Hadamard, J. (1945). An essay on the psychology of invention in the mathematical field. New York: Dover Publications.

Halmos, P. R. (1983). Mathematics as a creative art. In D. E. Sarason \& L. Gillman (Eds.), P.R. Halmos, selecta expository writing. New York: Springer. Reprinted from (1968) American Scientist, 56, 375-389.

Haylock, D. (1997). Recognizing mathematical creativity in school children. International Reviews on Mathematical Education, 29, 68-74. http://dx.doi.org/10.1007/s11858-997-0002-y

Hiebert, J., Carpenter, T. P., Fennema, E., Fuson, K. C., Wearne, D., Murray, H., ... \& Human, P. (2000). Making sense: Teaching and learning mathematics with understanding. Portsmouth: Heinemann Publishers. 
Imai, T. (2000). The influence of overcoming fixation in mathematics towards divergent thinking in open-ended mathematics problems on Japanese junior high school students. International Journal of Mathematical Education in Science and Technology, 31, 187-193. http://dx.doi. org/10.1080/002073900287246

Jauk, E., Benedek, M., \& Neubauer, A. C. (2014). The road to creative achievement: A latent variable model of ability, and personality predictors. European Journal of Personality, 28, 95-104. http://dx.doi.org/10.1002/per.1941.

Johnsen, S. K., \& Sheffield, L. J. (2012). Using the common core state standards for mathematics with gifted and advanced learners. Waco: Prufrock Press.

Kaufman, J. C., \& Beghetto, R. A. (2009). Beyond big and little: The four C model of creativity. Review of General Psychology, 13, 1-12. http://dx.doi.org/10.1037/a0013688

Kim, H., Cho, S., \& Ahn, D. (2003). Development of mathematical creative problem solving ability test for identification of gifted in math. Gifted Education International, 18, 164-174. http://dx.doi.org/10.1177/026142940301800206

Krutetskii, V. A. (1976). The psychology of mathematical abilities in school children. Chicago: University of Chicago Press.

Lander, L. J., \& Parkin, T. R. (1966). Counterexample to Euler's conjecture on sums of like powers. Bulletin of the American Mathematical Society, 72, 1079. Retrieved from http://projecteuclid.org/euclid.bams/1183528522

Leder, G. C., Pehkonen, E., \& Törner, G. (Eds.). (2002). Beliefs: A hidden variable in mathematics education? Dordrecht: Kluwer Academic Publishers.

Leu, Y., \& Chiu, M. (2015). Creative behaviours in mathematics: Relationships with abilities, demographics, affects and gifted behaviours. Thinking Skills and Creativity, 16, 40-50. doi:10.1016/j.tsc.2015.01.001.

Mann, E. L. (2006). Creativity: The essence of mathematics. Journal for the Education of the Gifted, 30, 236-260.

Mann, E. L. (2009). The search for mathematical creativity: Identifying creative potential in middle school students. Creativity Research Journal, 21, 338-348. http://dx.doi. org/10.1080/10400410903297402

McLeod, D. B. (1994). Research on affect and mathematics learning in the JRME: 1970 to the present. Journal for Research in Mathematics Education, 25, 637-647. Retrieved from http:// www.jstor.org/stable/749576.

McLeod, D. B., \& Adams, V. M. (1989). Affect and mathematical problem solving: A new perspective. New York: Springer.

Merkel, G., Uerkwitz, J., \& Wood, T. (1996). Criar um ambiente na aula para falar sobre a matemática. [Creating a context for talking about mathematical thinking]. Educacao $e$ Matematica, 4, 39-43. Retrieved from http://www.apm.pt/portal/index_loja.php?id= 23540\&rid $=21992$

Movshovitz-Hadar, N., \& Kleiner, I. (2009). Intellectual courage and mathematical creativity. In R. Leikin, A. Berman, \& B. Koichu (Eds.), Creativity in mathematics and education of gifted students (pp. 31-50). Rotterdam: Sense Publications.

National Council of Teachers of Mathematics. (2014, July). Procedural fluency in mathematics, Retrieved from http://www.nctm.org/Standards-and-Positions/Position-Statements/ Procedural-Fluency-in-Mathematics/

National Governors Association Center for Best Practices, \& Council of Chief State School Officers. (2010). Common core state standards for mathematics. Washington, DC: Authors.

National Research Council. (2000). How people learn: Brain, mind, experience, and school (Expandedth ed.). Washington, DC: The National Academies Press.

Nigstad, B., De Dreu, C. K. W., Rietzschel, E. R., \& Baas, M. (2010). The dual pathway to creativity model: Creative ideation as a function of flexibility and persistence. European Review of Social Psychology, 21, 34-77. http://dx.doi.org/10.1080/10463281003765323.

Renzulli, J. S. (1978). What makes giftedness? Reexamining a definition. Phi Delta Kappan, 60(180-184), 261. http://dx.doi.org/10.1177/003172171109200821 
Renzulli, J. S. (1998). Three-ring conception of giftedness. In S. M. Baum, S. M. Reis, \& L. R. Maxfield (Eds.), Nurturing the gifts and talents of primary grade students. Mansfield Center: Creative Learning Press. Retrieved from http://www.gifted.uconn.edu/sem/semart13.html

Renzulli, J. S. (2002). Expanding the conception of giftedness to include co-cognitive traits and to promote social capital. Phi Delta Kappan, 84, 33-58. http://dx.doi. org/10.1177/003172170208400109

Rogers, L. (2014). The history of negative numbers. Retrieved from: http://nrich.maths.org/5961

Runco, M. A. (2014). Chapter 9: Personality and motivation. In Creativity theories and themes: Research, development and practice (2nd ed., pp. 265-302). Amsterdam: Academic Press.

Runco, M. A., \& Albert, R. S. (1986). The threshold theory regarding creativity and intelligence: An empirical test with gifted and nongifted children. The Creative Child and Adult Quarterly, 11, 212-218. Retrieved from http://creativitytestingservices.com/satchel/pdfs/1986\%20 Runco\%20Albert\%20Threshold\%20Theory.pdf

Sriraman, B. (2006). Are giftedness and creativity synonyms in mathematics? Journal of Secondary Gifted Education, 17, 20-36. Retrieved from http://files.eric.ed.gov/fulltext/EJ746043.pdf

Sternberg, R. J. (2009). Great minds think different. Stanford Social Innovation Review, $7(1), 21-22 . \quad$ Retrieved from http://www.ssireview.org/book_reviews/entry/iconoclast_ gregory_bern

Tjoe, H. (2015). Giftedness and aesthetics: Perspective and expert mathematicians and mathematically gifted students. Gifted Child Quarterly, 59, 165-176. http://dx.doi. org/10.1177/0016986215583872

Torrance, E. P. (1966). The Torrance tests of creative thinking-norms-technical manual research edition-verbal tests, forms $A$ and B-figural tests, forms $A$ and B. Princeton: Personnel Press.

Torrance, E. P. (2008). Torrance tests of creative thinking: Norms-technical manual, verbal forms $A$ and $B$. Bensenville: Scholastic Testing Service.

Torrance, E. P., Ball, O. E., \& Safter, H. T. (2008). The Torrance tests of creative thinking Streamlined scoring guide for figural forms $A$ and B. Bensenville: Scholastic Testing Service.

Tuli, M. R. (1980). Mathematical creativity as related to aptitude for achievement in and attitude towards mathematics. (Doctoral dissertation, Panjab University, 1980). Dissertation Abstracts International, 42(01), 122.

van Dyke, F., \& Craine, C. V. (1997). Equivalent representations in the learning of algebra. The Mathematics Teacher, 90, 616-619. Retrieved from http://www.jstor.org/stable/27970324 


\section{Author Query}

Chapter No.: 5

0002760416

\begin{tabular}{|l|l|l|}
\hline Query & Details Required & Author's Response \\
\hline AU1 & $\begin{array}{l}\text { Please confirm if presentation and placement of the article note } \\
\text { are okay. }\end{array}$ & \\
\hline
\end{tabular}

